\title{
DESIGN AND DEVELOPMENT OF MILD COMBUSTION BURNER
}

\author{
M.M. Noor ${ }^{1,2}$, Andrew P.Wandel ${ }^{1}$ and Talal Yusaf ${ }^{3}$ \\ ${ }^{1}$ Computational Engineering and Science Research Centre, School of Mechanical and \\ Electrical Engineering, University of Southern Queensland (USQ), Australia \\ ${ }^{2}$ Faculty of Mechanical Engineering, Universiti Malaysia Pahang (UMP), Malaysia \\ ${ }^{3}$ National Centre for Engineering in Agriculture, USQ, Australia \\ Email: Muhamad.MatNoor@usq.edu.au
}

\begin{abstract}
This paper discusses the design and development of the Moderate and Intense Low oxygen Dilution (MILD) combustion burner using Computational Fluid Dynamics (CFD) simulations. The CFD commercial package was used to simulate preliminary designs for the burner before the final design was sent to the workshop for fabrication. The burner is required to be a non-premixed and open burner. To capture and use the exhaust gas, the burner was enclosed within a large circular shaped wall with an opening at the top. An external EGR pipe was used to transport the exhaust gas which was mixed with the fresh oxidant. To control the EGR and exhaust flow, butterfly valves were installed at the top opening as a damper to close the exhaust gas flow at a certain ratio for EGR and exhaust out to the atmosphere. High temperature fused silica glass windows were installed to view and capture images of the flame and analyze the flame propagation. The burner simulation shows that MILD combustion was achieved for the oxygen mole fraction of 3-13\%. The final design of the burner was fabricated and ready for the experimental validation.
\end{abstract}

Keywords: Exhaust gas recirculation; computational fluid dynamics; experimental setup; bluff-body MILD burner.

\section{INTRODUCTION}

The chemical reactions through combustion remain the most important source of energy. The combustion of fossil fuel is projected to fulfil about $80 \%$ of the total worldwide energy needs by the year 2030 (Maczulak, 2010). The conventional combustion process produces high pollution emissions and greenhouse gases (EIA, 2011; Ghoniem, 2011). Due to the energy needs and pollution emissions, combustion researchers are focusing on the improvement of the combustion efficiency, new combustion technology and combustion modeling (Merci, Naud, \& Roekaerts, 2007; Noor, Wandel, \& Yusaf, 2012a; Smith \& Fox, 2007). MILD combustion is a new combustion technology that produces lower pollution emissions and increases thermal efficiency (Cavaliere \& de Joannon, 2004; Dally, Karpetis, \& Barlow, 2002; Noor, Wandel, \& Yusaf, 2013a). This combustion is also called flameless oxidation or FLOX (Mancini, Schwoppe, Weber, \& Orsino, 2007; Wünning, 1991), low NOx (Orsino, Weber, \& Bollettini, 2001) and high-temperature air combustion (HiTAC) (Katsuki \& Hasegawa, 1998; Tsuji, Gupta, \& Hasegawa, 2003). MILD combustion has been investigated experimentally (Li, Mi, Dally, Craig, \& Wang, 2011; Rafidi \& Blasiak, 2006) and numerically (Noor, Wandel, \& Yusaf, 2012c; Parente, Galletti, \& Tognotti, 2011; Szegö, Dally, \& Christo, 2011) in various industrial applications. The main 
requirement for MILD combustion is oxygen dilution in the oxidant stream and for the mixture temperature to be above the self-ignition for the fuel. The oxygen dilution and the heating of the oxidizer can be achieved by the use of exhaust gas recirculation (EGR) (Katsuki \& Hasegawa, 1998; Yusaf, Noor, \& Wandel, 2013). The hot EGR will dilute the oxygen in the oxidant and preheat it. The oxygen content in the fresh air will reduce the dependence on the ratio of the fresh air and EGR. A requirement of MILD combustion is to preheat a mixture and dilute the oxygen content in the oxidant. In order to achieve this condition, EGR was utilized. From comparison of the flame observation for conventional combustion with $21 \%$ oxygen (Figure 1(a)) and MILD combustion (Figure 1(c)) with $2 \%$ oxygen (Gupta, Bolz, \& Hasegawa, 1999), the flame can hardly be seen when the oxygen level is $2 \%$. The temperature distribution was more homogeneous and this characteristic gives it an advantage over MILD combustion for many applications that need stable and distributed temperature throughout the combustion chamber.

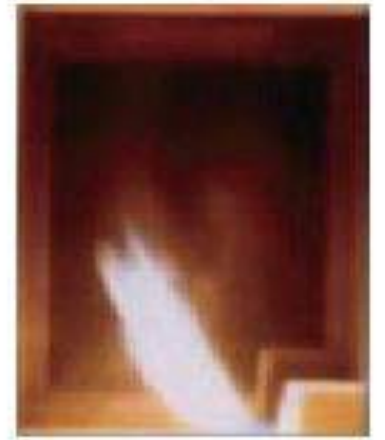

(a)

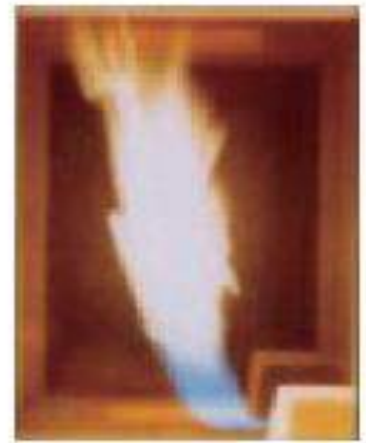

(b)

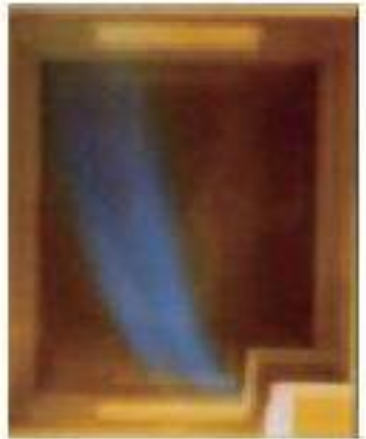

(c)

Figure 1. Combustion air temperature of $1100^{\circ} \mathrm{C}$ and percentage of $\mathrm{O}_{2}$ concentration: (a) $21 \%$ oxygen, (b) $8 \%$ oxygen, (c) $2 \%$ oxygen (Gupta et al., 1999)

The basic combustion process must be balanced as shown in Equation (1). The balanced combustion process will not produce unburned hydrocarbon (UHC) in the exhaust gas. This shows that the combustion process consumes all the fuel. The combustion process can be written in a general hydrocarbon stoichiometric combustion equation:

$$
C_{n} H_{m}+\left(n+\frac{m}{4}\right)\left(O_{2}+3.76 N_{2}\right) \rightarrow n C O_{2}+\frac{m}{2} H_{2} O+3.76\left(n+\frac{m}{4}\right) N_{2}
$$

The stoichiometric combustion equation without EGR for low calorific value gas consists of $50 \%$ methane, $20 \%$ hydrogen and $30 \%$ carbon dioxide by volume (Noor et al., 2012b).

$$
\begin{aligned}
\left(0.5 \mathrm{CH}_{4}+0.2 \mathrm{H}_{2}+0.3 \mathrm{CO}_{2}\right) & +\left(1.1 \mathrm{O}_{2}+4.1 \mathrm{~N}_{2}\right) \\
& \rightarrow\left(0.8 \mathrm{CO}_{2}+1.2 \mathrm{H}_{2} \mathrm{O}+4.1 \mathrm{~N}_{2}\right)
\end{aligned}
$$

In a more general form, the combustion equation without EGR is

$$
\begin{aligned}
\left(\mathrm{i} C H_{4}\right. & \left.+\mathrm{j} H_{2}+\mathrm{kCO} \mathrm{O}_{2}\right)+(2 \mathrm{i}+0.5 \mathrm{j})\left(1.0 \mathrm{O}_{2}+3.8 N_{2}\right) \\
& \rightarrow(\mathrm{i}+\mathrm{k}) \mathrm{CO}_{2}+(2 \mathrm{i}+\mathrm{j}) \mathrm{H}_{2} \mathrm{O}+(7.6 \mathrm{i}+1.9 \mathrm{j}) N_{2}
\end{aligned}
$$


where $i, j$ and $k$ are the mole fraction of the methane, hydrogen and carbon dioxide respectively. For lean combustion, we take the equivalent ratio, $\phi=0.5$ and the fuel composition is $i=0.5, j=0.2$ and $k=0.3$ :

$$
\begin{array}{r}
\left(0.25 \mathrm{CH}_{4}+0.1 \mathrm{H}_{2}+0.15 \mathrm{CO}_{2}\right)+\left(1.1 \mathrm{O}_{2}+4.1 \mathrm{~N}_{2}\right) \\
\rightarrow 0.4 \mathrm{CO}_{2}+0.6 \mathrm{H}_{2} \mathrm{O}+4.1 \mathrm{~N}_{2}+0.5 \mathrm{O}_{2}
\end{array}
$$

For rich combustion, we take the equivalent ratio, $\phi=1.5$ and the fuel composition is $i=0.5, j=0.2$ and $k=0.3$ :

$$
\begin{aligned}
& \left(0.75 \mathrm{CH}_{4}+0.3 \mathrm{H}_{2}+0.45 \mathrm{CO}_{2}\right)+\left(1.1 \mathrm{O}_{2}+4.1 \mathrm{~N}_{2}\right) \\
& \rightarrow 1.2 \mathrm{CO}_{2}+1.8 \mathrm{H}_{2} \mathrm{O}+4.1 \mathrm{~N}_{2}+0.5 \mathrm{CH}_{4}+0.5 \mathrm{H}_{2}
\end{aligned}
$$

and the combustion equation with EGR is

$$
\begin{aligned}
& \left(\mathrm{iCH}+\mathrm{j} \mathrm{H}_{2}+\mathrm{kCO}\right)+(2 \mathrm{i}+0.5 \mathrm{j})\left(1.0 \mathrm{O}_{2}+3.8 \mathrm{~N}_{2}\right) \\
& +\lambda\left[(\mathrm{i}+\mathrm{k}) \mathrm{CO}_{2}+(2 \mathrm{i}+\mathrm{j}) \mathrm{H}_{2} \mathrm{O}+3.8(2 \mathrm{i}+0.5 \mathrm{j}) \mathrm{N}_{2}\right] \\
& \quad \rightarrow(\lambda+1)\left[(\mathrm{i}+\mathrm{k}) \mathrm{CO}_{2}+(2 \mathrm{i}+\mathrm{j}) \mathrm{H}_{2} \mathrm{O}+3.8(2 \mathrm{i}+0.5 \mathrm{j}) N_{2}\right]
\end{aligned}
$$

where $\lambda$ is the EGR ratio. As stated above, the stoichiometric combustion equation for low calorific value gas consists of 50\% methane, $20 \%$ hydrogen and $30 \%$ carbon dioxide by volume. If $\lambda$ is 3.0 , then $75 \%$ of the flue gas will flow back to the chamber and lower the oxygen level in the oxidizer stream. For this composition at stoichiometric condition, $\phi=1.0$, the balance equation is

$$
\begin{gathered}
\left(0.5 \mathrm{CH}_{4}+0.2 \mathrm{H}_{2}+0.3 \mathrm{CO}_{2}\right)+\left(1.1 \mathrm{O}_{2}+4.1 \mathrm{~N}_{2}\right) \\
+\left(2.4 \mathrm{CO}_{2}+3.6 \mathrm{H}_{2} \mathrm{O}+12.4 \mathrm{~N}_{2}\right) \rightarrow\left(3.2 \mathrm{CO}_{2}+4.8 \mathrm{H}_{2} \mathrm{O}+16.5 \mathrm{~N}_{2}\right)
\end{gathered}
$$

For lean combustion, the excess oxygen and nitrogen will not be involved in combustion and exhaust through the flue gas. These excesses can be seen in an example (Equation 8) of $\phi=0.5$, and $33 \%$ EGR, when the balance equation is

$$
\begin{gathered}
\left(0.25 \mathrm{CH}_{4}+0.1 \mathrm{H}_{2}+0.15 \mathrm{CO}_{2}\right)+\left(1.1 \mathrm{O}_{2}+4.1 \mathrm{~N}_{2}\right) \\
+0.2 \mathrm{CO}_{2}+0.3 \mathrm{H}_{2} \mathrm{O}+2.1 \mathrm{~N}_{2} 0.4 \mathrm{O}_{2} \rightarrow 0.6 \mathrm{CO}_{2}+0.9 \mathrm{H}_{2} \mathrm{O}+6.2 \mathrm{~N}_{2}+1.1 \mathrm{O}_{2}
\end{gathered}
$$

In the rich combustion process, as there is not enough oxygen to burn a high mass fraction of $\mathrm{CH}_{4}$, excess methane and hydrogen will not be involved in combustion and will become unburned hydrocarbons. These conditions can be seen in an example (Equation 9) of $\phi=1.5$, and $66 \% \mathrm{EGR}$, when the balance equation is

$$
\begin{aligned}
& \left(0.75 \mathrm{CH}_{4}+0.3 \mathrm{H}_{2}+0.45 \mathrm{CO}_{2}\right)+\left(1.1 \mathrm{O}_{2}+4.1 \mathrm{~N}_{2}\right) \\
& +2.4 \mathrm{CO}_{2}+3.6 \mathrm{H}_{2} \mathrm{O}+8.3 \mathrm{~N}_{2}+1.1 \mathrm{CH}_{4}+1.1 \mathrm{H}_{2} \rightarrow \\
& \text { 3.6 } \mathrm{CO}_{2}+5.4 . \mathrm{H}_{2} \mathrm{O}+12.4 \mathrm{~N}_{2}+1.7 \mathrm{CH}_{4}+1.7 \mathrm{H}_{2}
\end{aligned}
$$

If the fuel is biogas with only methane and carbon dioxide, the general form of the combustion equation with EGR is

$$
\left(\mathrm{i} \mathrm{CH}_{4}+\mathrm{kCO} \mathrm{O}_{2}\right)+2 \mathrm{i}\left(1.0 \mathrm{O}_{2}+3.8 N_{2}\right)+\lambda\left[(\mathrm{i}+\mathrm{k}) \mathrm{CO}_{2}+2 \mathrm{i} \mathrm{H}_{2} O+7.6 \mathrm{i} \mathrm{N}_{2}\right]
$$




$$
\rightarrow(\lambda+1)\left[(\mathrm{i}+\mathrm{k}) \mathrm{CO}_{2}+2 \mathrm{i} \mathrm{H}_{2} \mathrm{O}+7.6 \mathrm{i} N_{2}\right]
$$

The development of a MILD burner for non-premixed open flame was discussed. The burner was designed using ANSYS Fluent 14.5 to numerically simulate and predict the behavior of combustion and flame. The burner was then built at the USQ mechanical workshop. Methane, biogas and coal seam gas (CSG) will be used in the testing and experimental work. In order to design the combustion chamber, the basics of the combustion equation must be used to calculate the air fuel ratio (AFR). The study of the AFR using computational fluid dynamics was done to design the air and fuel inlet diameters and volume flow rates (Noor, Wandel, \& Yusaf, 2012b).

\section{CFD SIMULATIONS}

The application of computer simulation techniques to improve many complex processes, including the combustion process, has rapidly expanded over the last decade. CFD is an important design tool that has been extensively used to explore and design engineering hardware (Baukal, Gershtein, \& Li, 2001; Davidson, 2002) including combustion chambers. Moreover, computational simulation frequently provides information on physical quantities that are difficult to measure. CFD is increasingly being used for the optimization of gas burners (Scharler \& Obernberger, 2000) and industrial gas furnaces (Dally, Riesmeier, \& Peters, 2004; Noor et al., 2013a; Riahi, Mergheni, Sautet, \& Nasrallah, 2012) or coal combustion (Calchetti, Nardo, Mongibello, \& Mongiello, 2007). In this study, the CFD was used to model MILD combustion in the mode of non-premixed combustion. The second order scheme was used to discretize the governing equations, including mass, momentum, energy and species in addition to the turbulence transport and combustion model. The realizable $\mathrm{k}-\varepsilon$ turbulence model (Shih, Liou, Shabbir, Yang, \& Zhu, 1995) [that was developed based on the standard k- $\varepsilon$ turbulence model (Launder \& Spalding, 1974)] was used for the turbulence model (Peters, 2000; Pope, 2000) and discrete ordinate (DO) model (Chui \& Raithby, 1993) for the radiation model. The DO model is applicable to a wide range of optical thicknesses. The optical thickness for MILD combustion flames is not well defined, which makes the DO model a good choice for the radiation model. This model is solved as a radiative transfer equation. The weighted sum of gray gases model (WSGGM) was used for the absorption coefficient which was conceptually developed in 1967 (Hottel \& Sarofim, 1967) and used for spray combustion (Choi \& Baek, 1996) and gas furnaces (Liu, Becker, \& Bindar, 1998). The WSGGM is a reasonable compromise between the oversimplified gray gases model and a complete model. Meshing was done using an advanced size function and the details of the meshing as shown are based on Noor, Wandel, and Yusaf (2013b). At the beginning of the simulation, the meshing used is a medium size to ensure that the simulation achieves the result quickly. The MILD combustion open furnace was modeled and the flame behavior, temperature distributions, flow velocities, turbulent behavior and EGR flow were analyzed. The early design of the combustion chamber was with 2 EGR and 4 small EGR pipes to transport the exhaust gas to mix it with fresh air. Those two models were not successful in ensuring the exhaust gas would go into the EGR pipe and flow down. This was because the EGR inlet was perpendicular to the exhaust pipe which did not help the fluid flow. The $90^{\circ}$ inlet angle did not let the exhaust gas flow into the EGR pipe as planned. The design for the EGR inlet was therefore changed with the inlet in a vertical direction. This is in line with the direction of the flame and exhaust gas and 
makes it easier for the exhaust gas to flow into the EGR pipe. The outlet for the exhaust was also lowered to assist the exhaust gas flow into the EGR inlet.

The small EGR pipe only allows a small volume of exhaust gas to flow downward. In order to increase the volume of the exhaust gas flow, the whole diameter of the EGR pipe was increased from $25 \mathrm{~mm}$ to $50 \mathrm{~mm}$. To assist the EGR flow downward, a fresh air inlet was installed on the side of each EGR (Figure 2(a)). The purpose of this design is also to ensure that the exhaust gas mixes properly before entering the combustion chamber. Nakamura, Smart, and Van de Kamp (1993) and (Weber, Orsino, Lallemant, \& Verlann, 2000; Weber, Smart, \& Kamp, 2005) experimentally studied pilot-scale furnaces equipped with heat exchangers and demonstrated that heat transfer was affected by the port locations and angles. After finalizing the pre-design, the simulation was done on the final model (Figure 2) for the ignition location study (Noor et al., 2013a), air fuel ratio study (Noor et al., 2012b) and other parametric studies (Noor et al., 2012c) on the MILD combustion using biogas as a fuel. Different combinations of air and fuel compositions injected into the chamber gave different results.

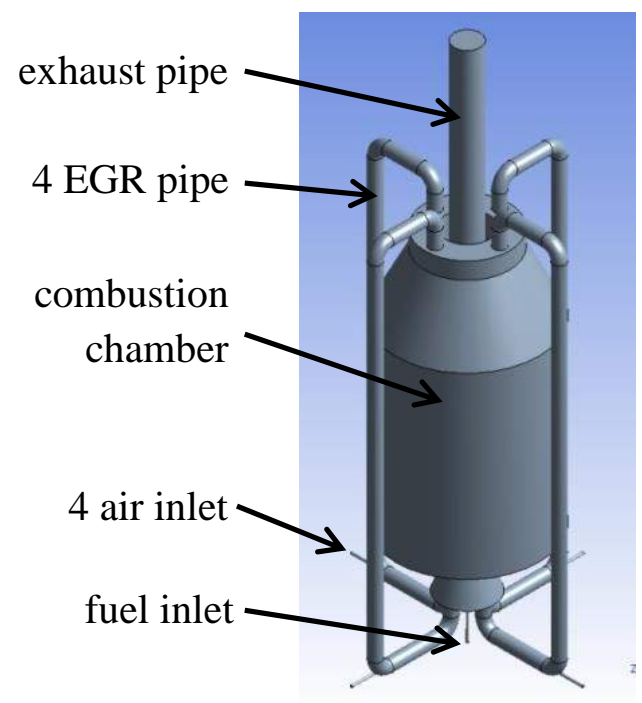

(a)

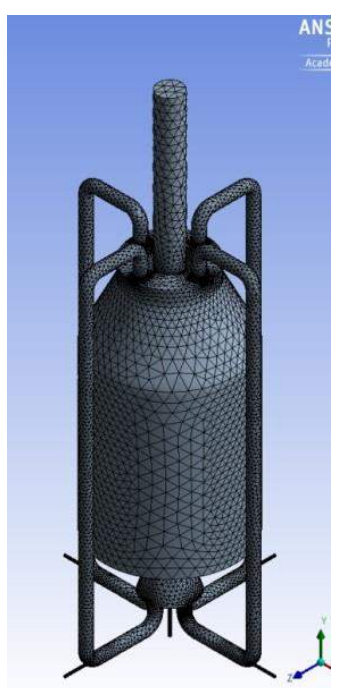

(b)

Figure 2. Final design with bigger EGR pipe: (a) schematic diagram with boundary condition; (b) model after meshing

Figure 3 shows the velocity magnitude inside the combustion chamber. This flow shows that the chamber is open and that the chamber is at atmospheric pressure since the chamber is open on the top. This open chamber is considered to be an open combustion furnace. Figure 3 shows that the exhaust gas mainly flows out through the top opening and some of the exhaust gas flows through the EGR pipe as required. This result is in accordance with earlier research (Figure 4) that shows the main stream of the exhaust flowing out through the top exhaust pipe. Figure 5 shows the mole fraction of methane between 0 and 0.6 (Figure 5(a)) and between 0 and 0.05 (Figure 5(b)). This condition shows that all the methane was consumed by combustion and that almost zero unburned hydrocarbon will be released through the exhaust gas and EGR pipe. This happens when the combustion is reaching a stoichiometric condition with a lambda ratio of 1.0. 


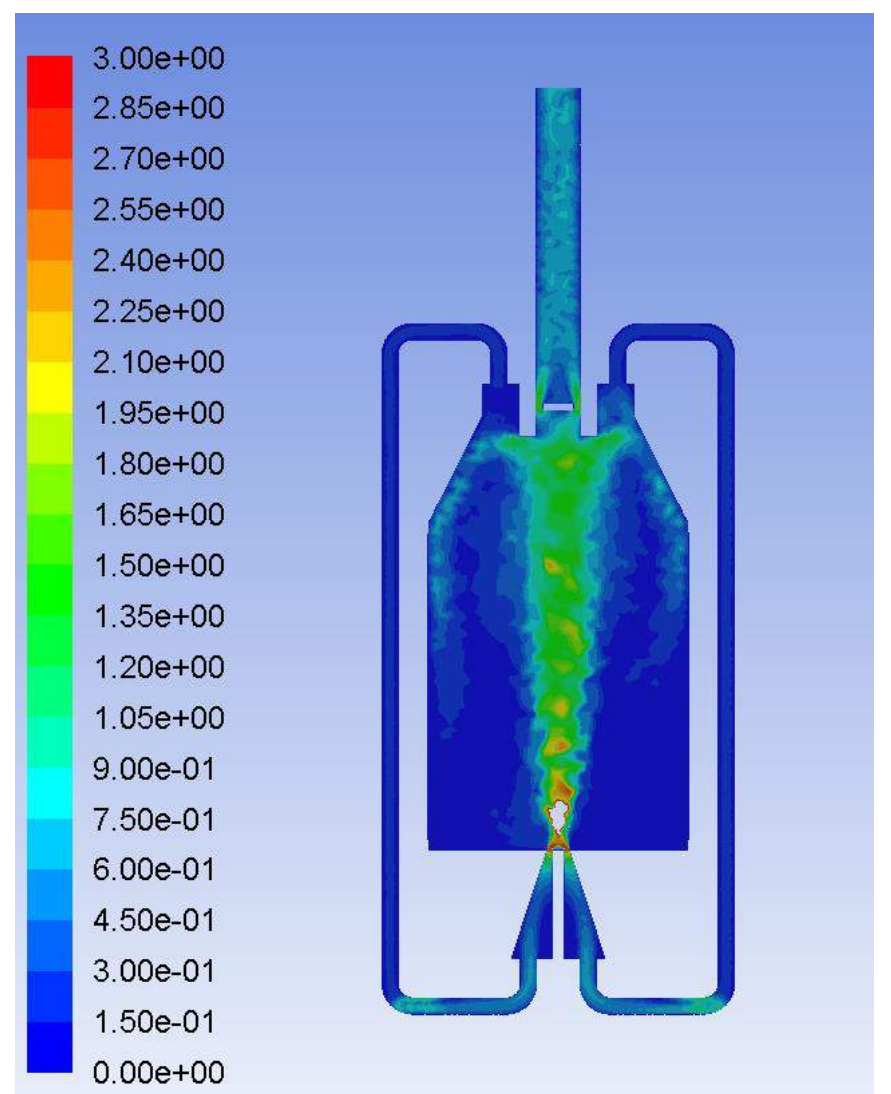

Figure 3. Velocity magnitude inside the combustion chamber

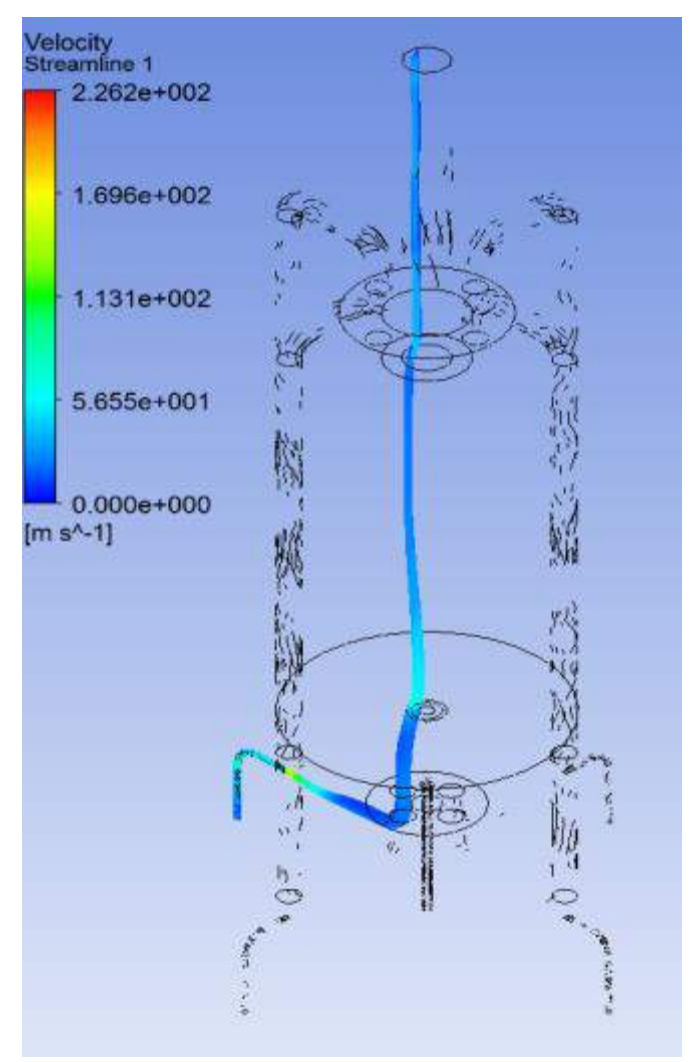

Figure 4. Velocity magnitude inside the combustion chamber (Noor et al., 2012c). 


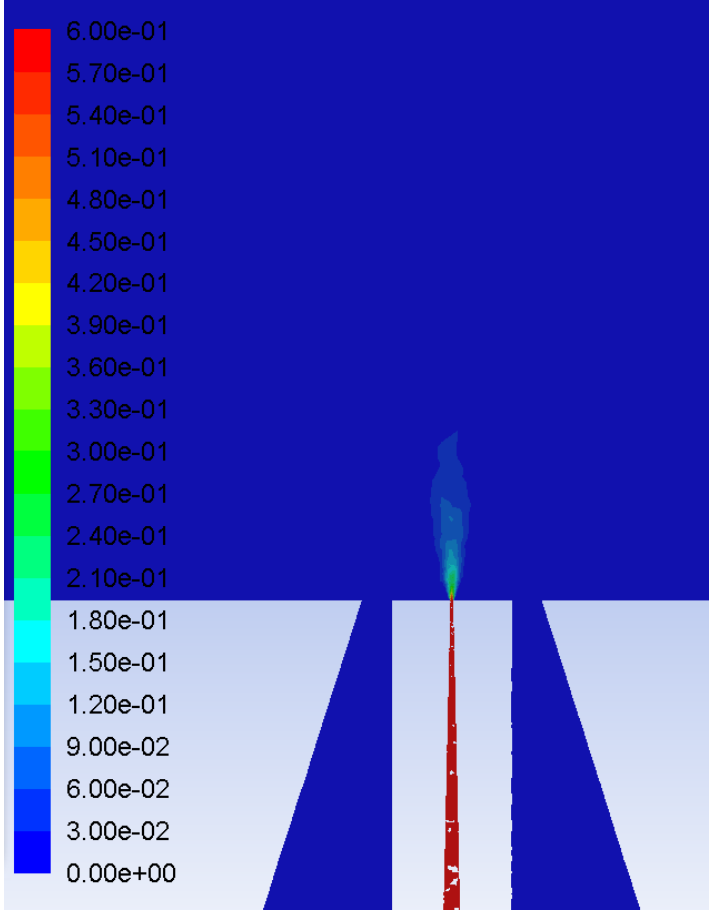

(a)

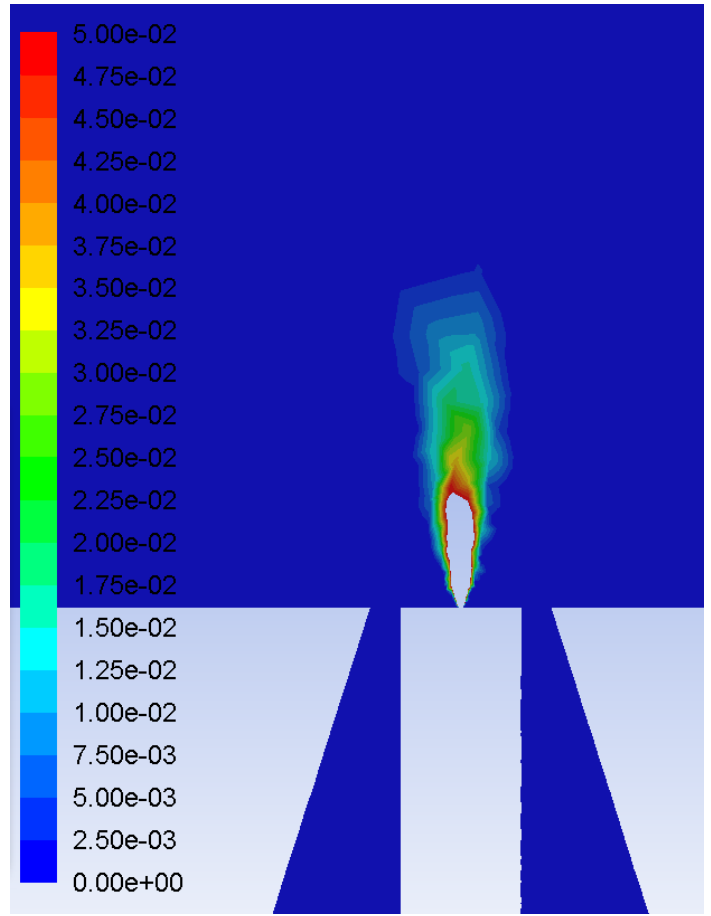

(b)

Figure 5. Mole fraction of $\mathrm{CH}_{4}$ species (a) between 0 and 0.6 (b) between 0 and 0.05

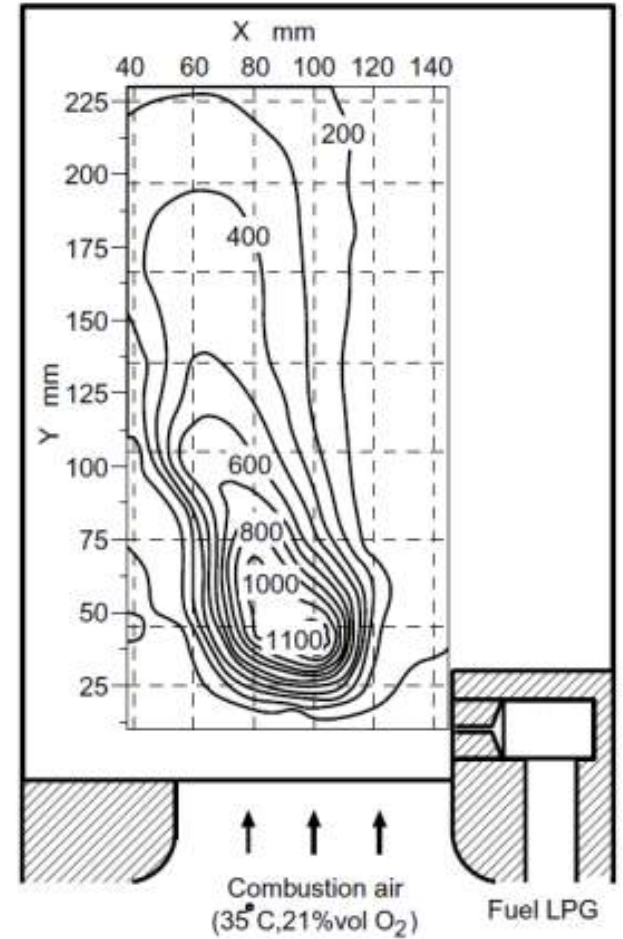

(a)

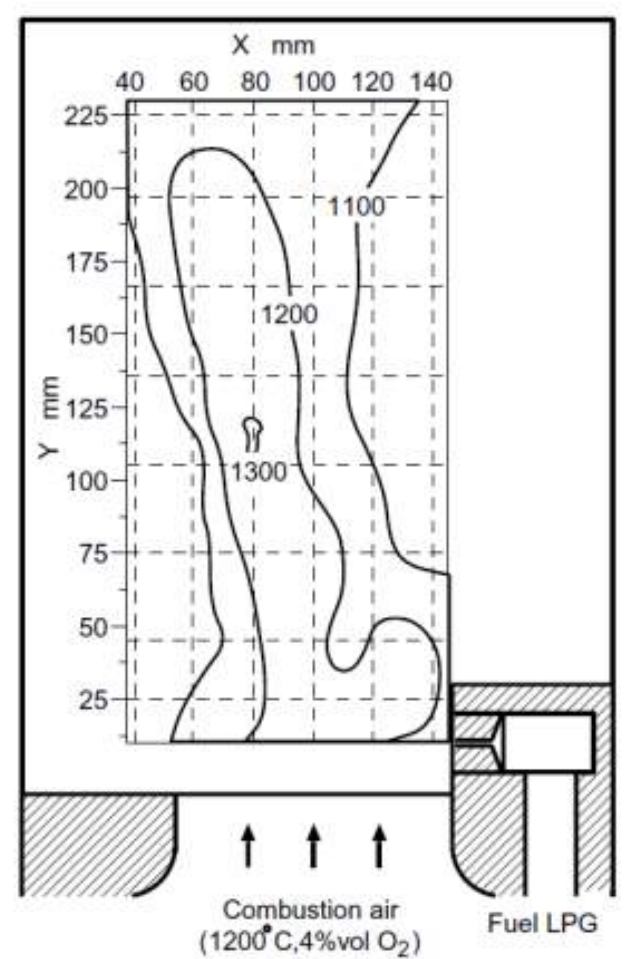

(b)

Figure 6. Combustion temperature distribution: (a) conventional combustion; (b) MILD combustion (Tsuji et al., 2003) 
The homogeneous temperature of MILD combustion is presented in Figure 6, comparing the temperature contour for conventional combustion (Figure 6(a)) with room temperature oxidant at $21 \%$ oxygen mole fraction, and MILD combustion (Figure 6(b)) with preheated oxidant at $4 \%$ (lower) oxygen mole fraction (Tsuji et al., 2003). The temperature distribution for conventional combustion is between $100 \mathrm{~K}$ and $1100 \mathrm{~K}$, which is a $91 \%$ difference from the lowest to the highest temperature, which is not a homogeneous temperature. The temperature distribution for conventional combustion is between $1000 \mathrm{~K}$ and $1300 \mathrm{~K}$, which is a $23 \%$ difference from the lowest to the highest temperature, which is a homogeneous temperature. In this study, with the oxygen level from 3 to $13 \%$ before it is mixed with fuel, MILD combustion will be achieved (Figure 7(b)). Otherwise, combustion is not achieved in the MILD state (Figure 7(a)) (Noor et al., 2012a).

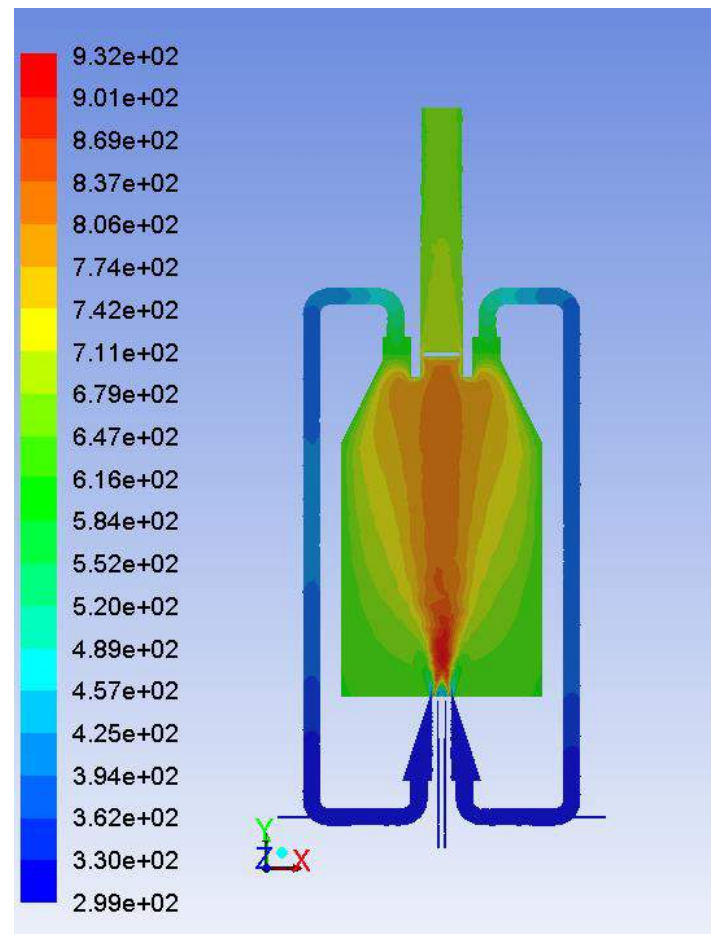

(a)

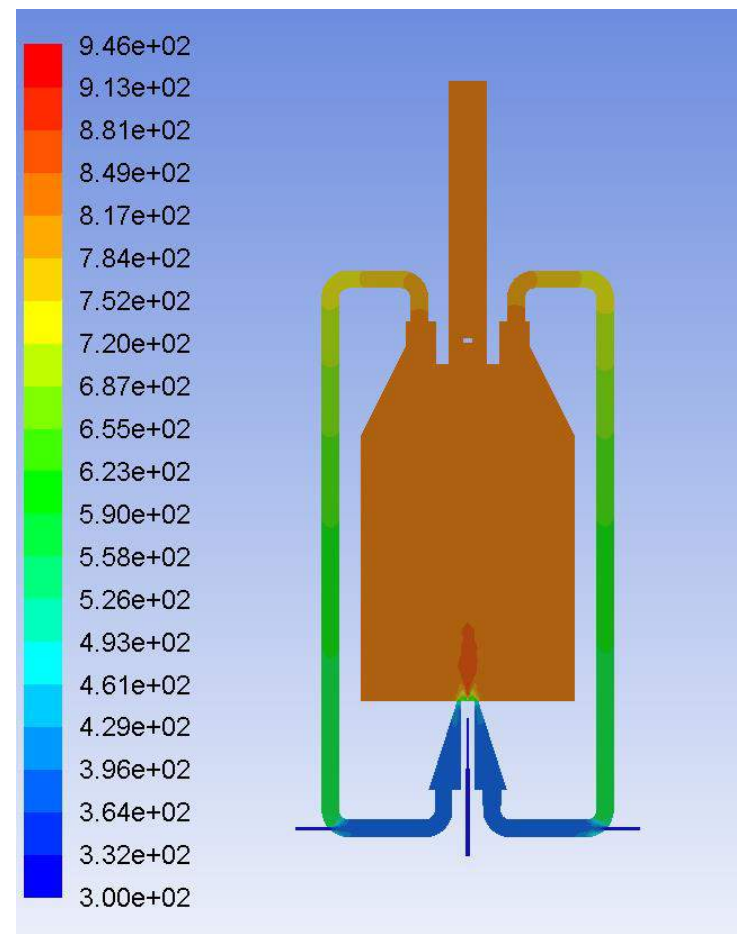

(b)

Figure 7. MILD combustion state: (a) not achieved; (b) achieved

\section{MODEL FABRICATION}

The lab scale furnace design was finalized and the fabrication was undertaken in the USQ mechanical workshop. There are 3 main parts: the gas system, burner and data acquisition. The gas system includes 5 gas cylinders, a gas supply line and valve and a gas control panel. The gas control panel was placed where the gas is mixed and the flow rate is controlled. Further detail about the data acquisition is discussed in the next section. Figure 8 shows the burner with 3 high-temperature fused silica observation windows and the gas control panel. 


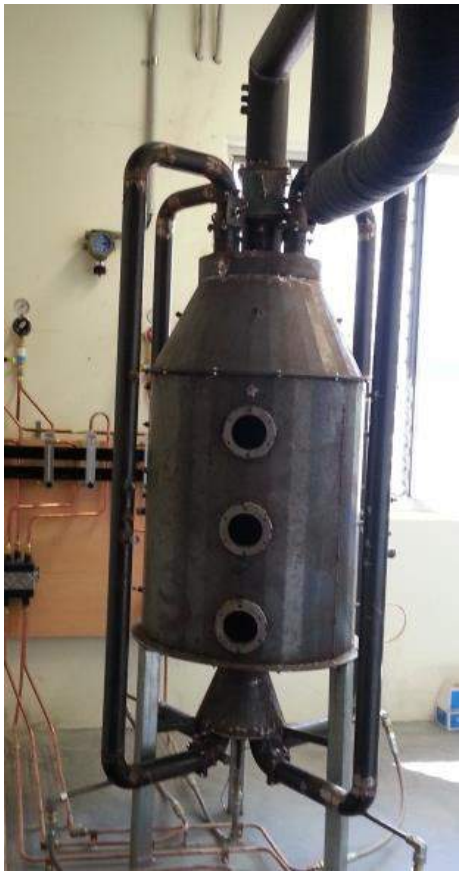

(a)

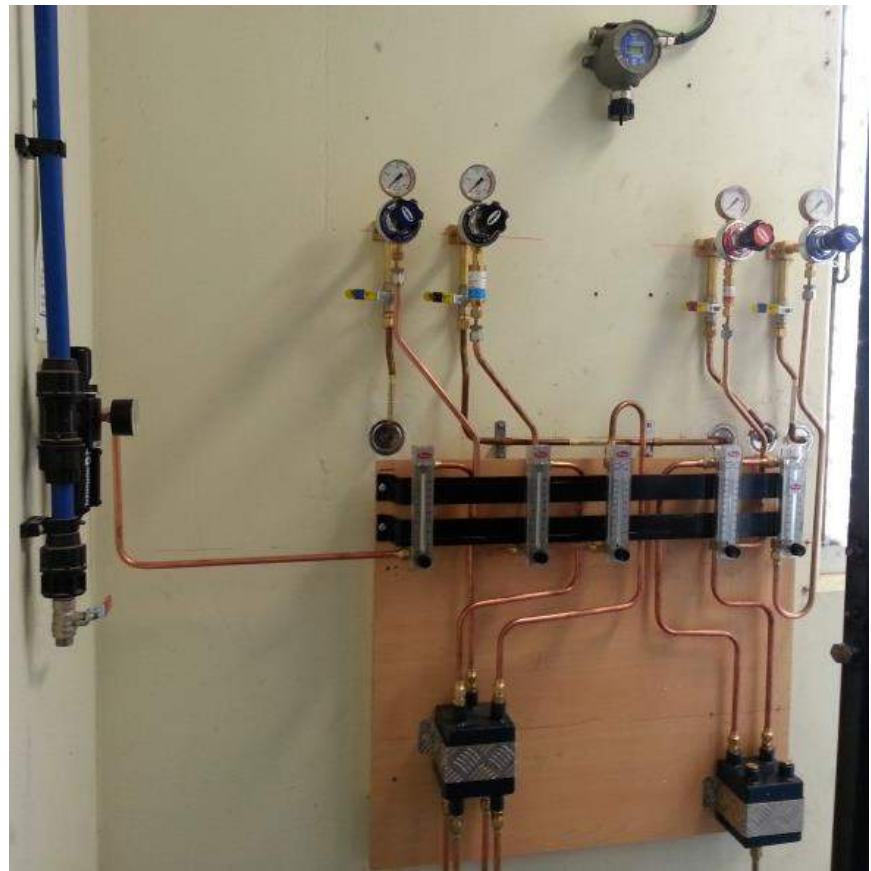

(b)

Figure 8. MILD burner setup: (a) with three glass windows; (b) gas control panel

The combustion process needs an ignition system to start the flame. The ignition process is one of the important study parameters for the burner and was designed using a spark ignition in the recirculation zone (Noor et al., 2013a). A study on the recirculation zone for the ignition location was done using CFD. Figure 9(a) shows the flame flow field, with Figure 9(b) as the mixing recirculation zone. Figure 9(b) shows that there are two types of recirculation zone: the inner recirculation zone (IRZ) is formed in between the air and the fuel jet flow of the bluff-body and the outer recirculation zone (ORZ) is formed outside the annulus air flow. The recirculation of the mixture of fuel and air was important because the process will create a turbulent flow of the mixture which will enhance the mixing process. Mastorakos (2009), Triantafyllidis, Mastorakos, and Eggels (2009), Neophytou, Richardson, and Mastorakos (2012) and Noor et al. (2013a) concluded that the best location for ignition was in the center of the inner recirculation zone where the recirculation velocity is almost zero. This is important to ensure that the spark energy supplied by the tungsten rod is not flushed away, thereby giving sufficient time for the spark energy to ignite the mixture of fuel and oxidant. The ignition system was designed and installed as shown in Figures 10 and 11. The ignition system comes with 2 tungsten rods, each with a diameter of $2.4 \mathrm{~mm}$. At the end of the tungsten rod, the sharp edge has a gap at $2.0 \mathrm{~mm}$. An ignition coil was used to increase the voltage from the car battery and used to ignite the mixture. The ignition installation is shown in Figure 11. The gas control panel regulates the gas flow rate and the mixing of gas. The gas supplies are methane, carbon dioxide, oxygen and nitrogen. Methane and carbon dioxide were used to mix and create biogas, with a composition of $60 \%$ methane and $40 \%$ carbon dioxide. More study can be undertaken to investigate the effect of different proportions of methane and carbon dioxide as a fuel. For the oxidant, beside the atmospheric air with $21 \%$ oxygen mole fraction, oxygen and nitrogen were used to create the synthetic air supply, with oxygen levels at around 3 to $30 \%$ in the mixture. 


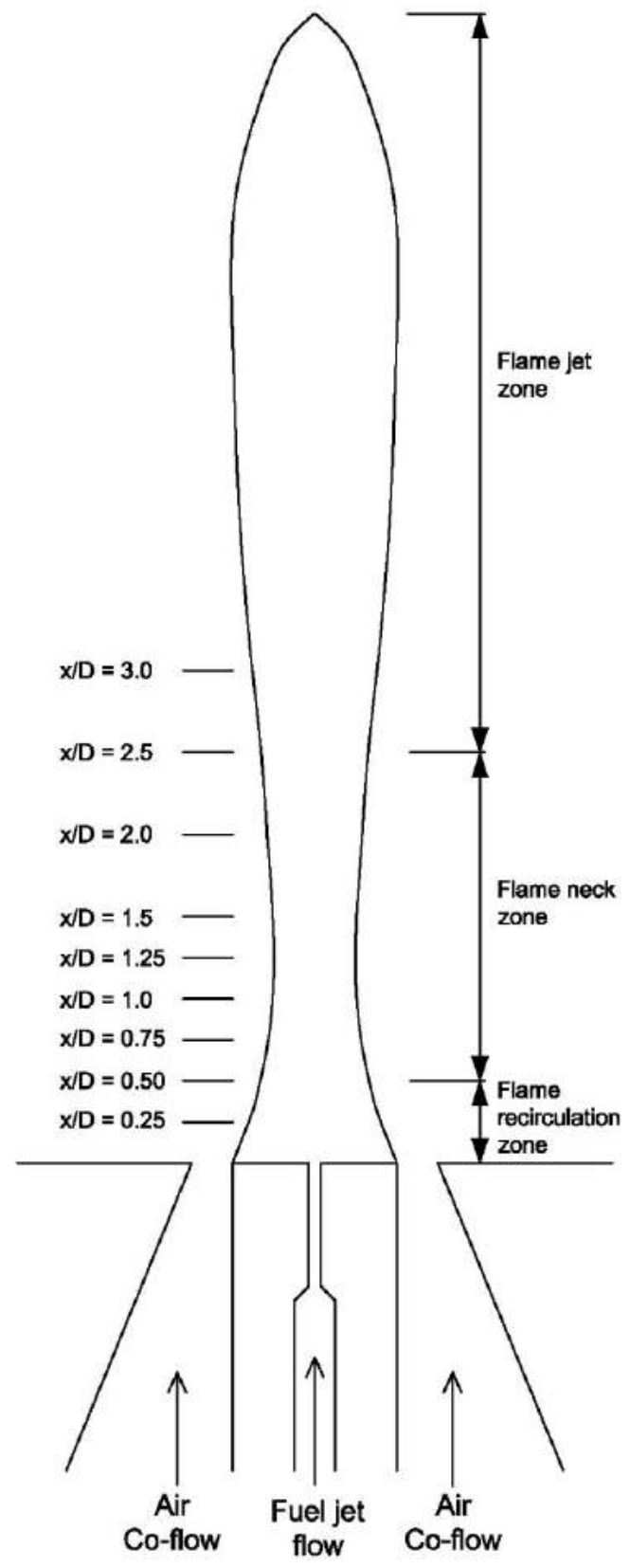

(a)

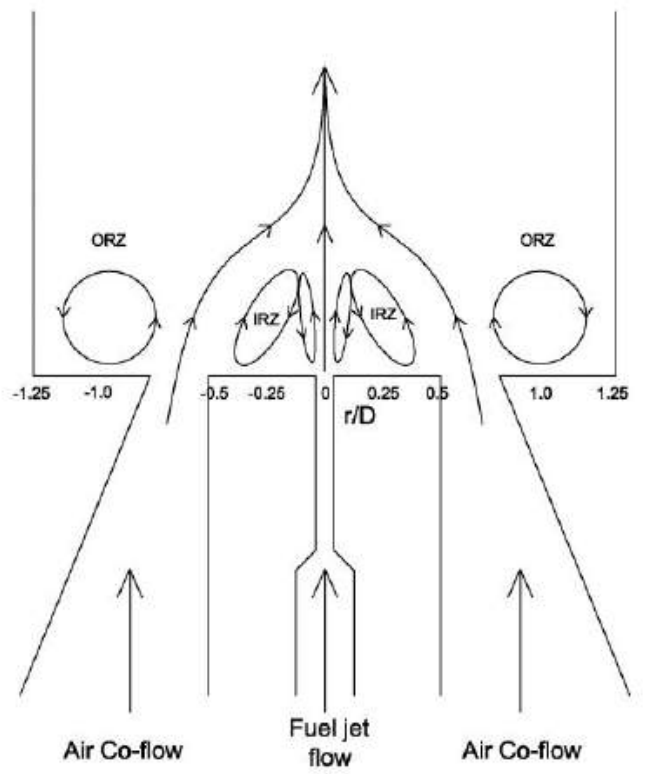

(b)

Figure 9. Schematic diagrams for bluff-body burner: (a) flame flow field with central fuel jet and annulus air co-flow; (b) flow field re-circulation zone 


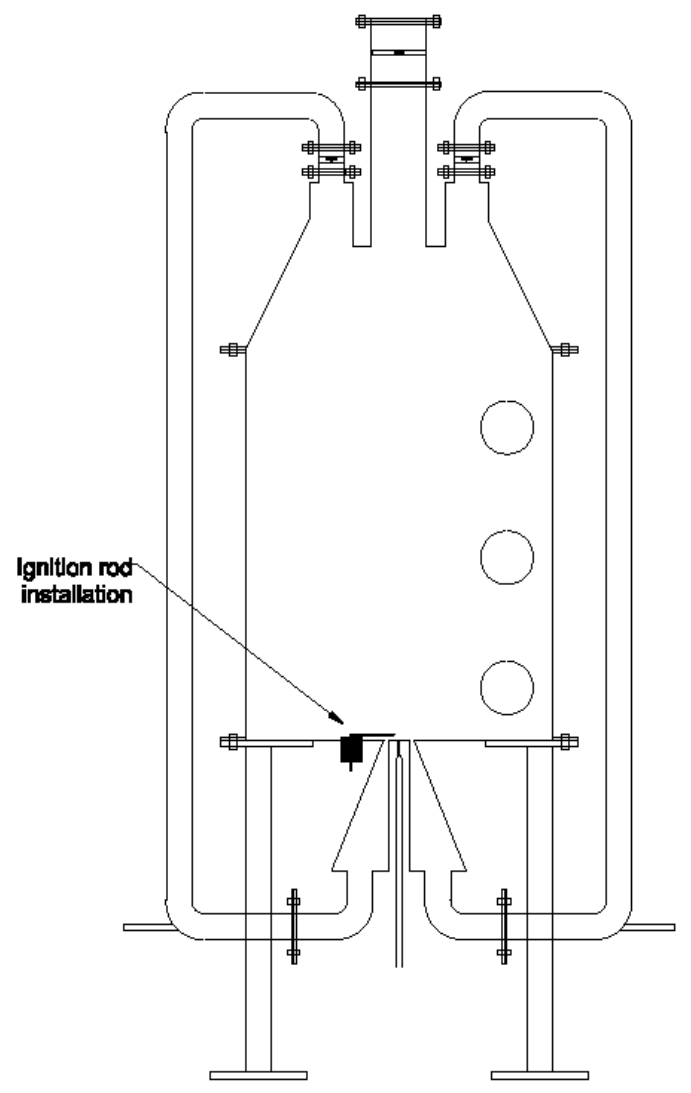

(a)

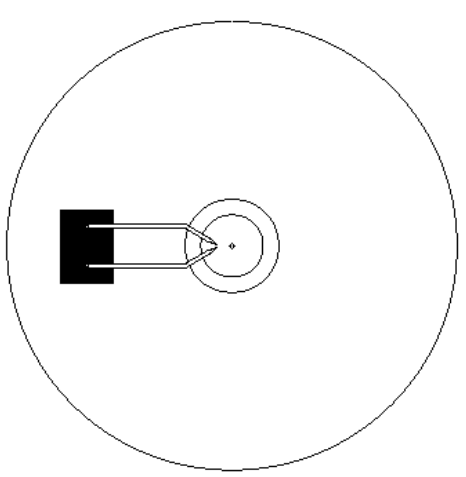

(b)

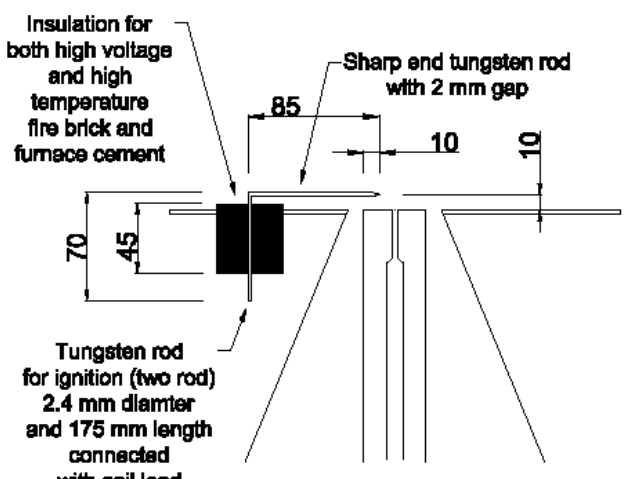

(c)

Figure 10. Schematic diagrams of combustion chamber: (a) ignition rod location; (b) location plan view; and (c) side view of ignition location and installation

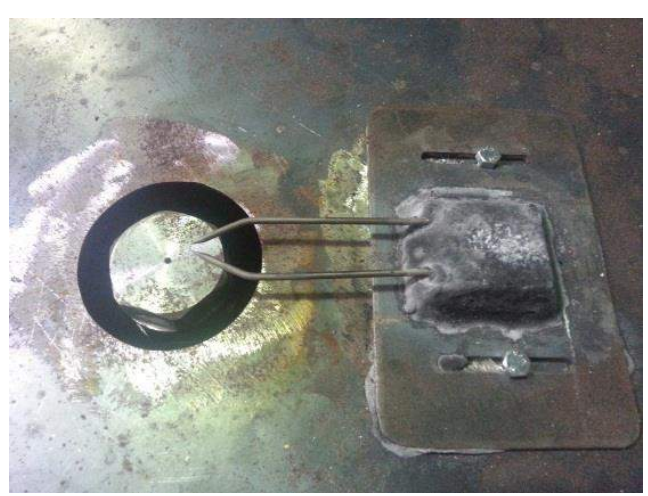

(a)

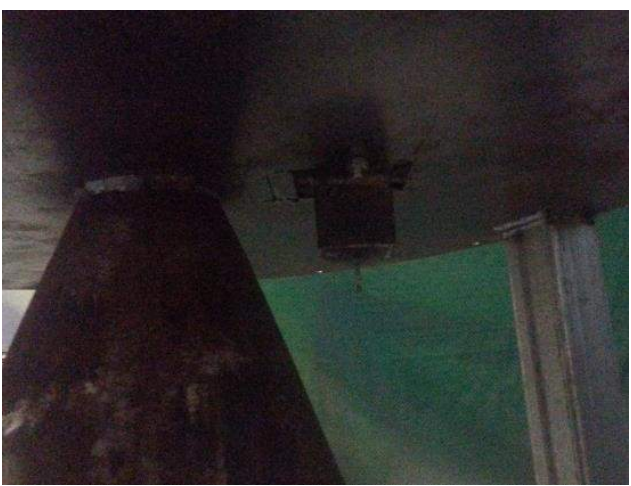

(b)

Figure 11. Ignition system: (a) ignition lead top view (inside the burner); (b) bottom view (outside the burner)

\section{HEAT RELEASE RATE}

The heat release rate is the important feature for the furnace. Furnaces are normally rated based on the power release in kilowatts $(\mathrm{kW})$. The furnace power or heat release rate can be calculated by the mass flow rate $(\mathrm{kg} / \mathrm{s})$ multiplied by the gas heating value $(\mathrm{kJ} / \mathrm{kg})$. If methane is injected through a $10 \mathrm{~mm}$ inlet diameter, the area of the fuel inlet 
is $7.85 \times 10^{-5} \mathrm{~m}^{2}$. The gas is injected into the combustion chamber at a maximum rate of 25.0 liter/min. This is equal to $4.16 \times 10^{-4} \mathrm{~m}^{3} / \mathrm{s}$. The fuel injection speed is $5.3 \mathrm{~m} / \mathrm{s}$. The mass flow rate depends on the density of the fluid. The density of methane gas is 0.668 $\mathrm{kg} / \mathrm{m}^{3}$ (at $293 \mathrm{~K}$ and $101.325 \mathrm{kPa}$ ), so the mass flow rate is $2.78 \times 10^{-4} \mathrm{~kg} / \mathrm{s}$, which is gas density times volume flow rate. The heat release by the combustion of methane can be calculated by using the methane heating value $(55.0 \mathrm{MJ} / \mathrm{kg})$. The heat release is 15.3 $\mathrm{kW}$, which is the mass flow rate times the gas heating value. The heat release rate or furnace power for the furnace at 25 liter/minute of methane volume flow rate is 15.3 $\mathrm{kW}$. The methane thermal properties include internal energy (u), enthalpy, (h), specific heat $\left(\mathrm{C}_{\mathrm{p}}\right)$, and heating value (hv). The heating value unit is $\mathrm{J} / \mathrm{mole}$ or Joule $/ \mathrm{kg}$, used to measure the maximum amount of heat that can be generated by combustion with air at $25^{\circ} \mathrm{C}$ and $101.325 \mathrm{kPa}$. The highest heating value is hydrogen, which is $141.8 \mathrm{~kJ} / \mathrm{kg}$, while methane is $55.5 \mathrm{~kJ} / \mathrm{kg}$, the highest among the hydrocarbon fuels.

\section{TEMPERATURE SENSORS AND DATA COLLECTION}

Thermocouples were installed at 35 different locations on the combustion chambers such as the main chamber, air inlet, EGR and exhaust pipe. The computer used for data recording is equipped with a National Instrument (NI) data acquisition system and LabVIEW software. The temperature was measured using R-type and K-type thermocouples which were connected to an NI connector box. The measurement was displayed and recorded in a LabVIEW graphical user interface (GUI) and can be recorded and displayed in the format of an MS Excel spreadsheet. In this experiment, the National Instruments Data Acquisition (NIDAQ) system was used to measure and display the temperature measurement through thermocouples. LabVIEW software was used to manage and store the data collected. It consists of a chassis NIDAQ 9178 with a number of signal conditioning amplifiers and analog to digital conversion modules. Gas analyzers were used to measure the gas composition in the combustion chamber, EGR pipe and exhaust ducting. The analysis of gas composition is very important when evaluating $\mathrm{NO}_{\mathrm{x}}$ emissions, unburned hydrocarbon (UHC) and excess oxygen in the exhaust gas.

\section{CONCLUSIONS}

In summary, the simulation of the MILD combustion was successful in achieving a MILD combustion regime. The CFD was successfully utilized to develop an open furnace for MILD combustion. The combustion has to be enclosed to collect the exhaust gas and utilized to dilute the oxygen in the oxidant stream and, at the same time, increase the oxidant temperature. Four EGR pipes were added to bring down the exhaust gas and mix it with the inlet air. The building and development of the furnace was carried out at the University of Southern Queensland mechanical workshop. The furnace was equipped with three high-temperature glass windows to monitor and record the flame propagation. The R-type thermocouple was used for the main chamber temperature measurement since it can withstand up to $2040 \mathrm{~K}$. A K-type thermocouple that can withstand up to $1645 \mathrm{~K}$ was used to measure the temperature of the exhaust gas at the exhaust gas pipe on the top of the chamber and in the EGR pipe. A data acquisition system was used to collect and record the data from the thermocouples. The composition of the exhaust gas in the exhaust pipe and EGR pipe was measured using 
gas analyzers. The furnace power calculated for the 25 liter/minute of methane is 15.3 $\mathrm{kW}$.

\section{ACKNOWLEDGMENTS}

The authors would like to thank the University of Southern Queensland (USQ), Ministry of Higher Education, Malaysia (MOHE) and Universiti Malaysia Pahang (UMP) for providing financial support and laboratory facilities. The first author also thanks A.A. Hairuddin (UPM), C. Galligan and B. Aston (USQ Mechanical Workshop) and Dr. Paul Baker (USQ combustion laboratory) for the discussions.

\section{REFERENCES}

Baukal, C. E., Gershtein, V. Y., \& Li, X. (2001). Computational fluid dynamics in industrial combustion. Boca Raton, Florida: CRC Press.

Calchetti, G., Nardo, A. D., Mongibello, G., \& Mongiello, C. (2007). Mild combustion simulation of coal water slurry. Paper presented at the Italian Section of the Combustion Institute 30th Meeting on Combustion, Ischia, Italy.

Cavaliere, A., \& de Joannon, M. (2004). Mild combustion. Progress in Energy and Combustion Science, 30(4), 329-366.

Choi, C. E., \& Baek, S. W. (1996). Numerical analysis of a spray combustion with nongray radiation using weighted sum of gray gases model. Combustion Science and Technology, 115(4-6), 297-315.

Chui, E. H., \& Raithby, G. D. (1993). Computation of radiant heat transfer on a nonorthogonal mesh using the finite-volume method. Numerical Heat Transfer, Part B: Fundamentals, 23(3), 269-288.

Dally, B. B., Karpetis, A. N., \& Barlow, R. S. (2002). Structure of turbulent nonpremixed jet flames in a diluted hot coflow. Proceedings of the Combustion Institute, 29(1), 1147-1154.

Dally, B. B., Riesmeier, E., \& Peters, N. (2004). Effect of fuel mixture on moderate and intense low oxygen dilution combustion. Combustion and Flame, 137(4), 418431.

Davidson, D. L. (2002). The role of computational fluid dynamics in process industries. The Bridge, 32(4), 9-14.

EIA. (2011). Annual energy review Technical report DOE/EIA-0484. Washington DC, United States: Energy Information Administration, US Department of Energy

Ghoniem, A. F. (2011). Needs, resources and climate change: Clean and efficient conversion technologies. Progress in Energy and Combustion Science, 37, 1551.

Gupta, A. K., Bolz, S., \& Hasegawa, T. (1999). Effect of air preheat temperature and oxygen concentration on flame structure and emission. Journal of Energy Resources Technology, 121, 209-216.

Hottel, H. C., \& Sarofim, A. F. (1967). Radiative transfer. New York: McGraw Hill.

Katsuki, M., \& Hasegawa, T. (1998). The science and technology of combustion in highly preheated air. Paper presented at the Proceedings of Combustion Institute.

Launder, B. E., \& Spalding, D. B. (1974). The numerical computation of turbulent flows. Computer Methods in Applied Mechanics and Engineering, 3(2), 269289. 
Li, P. F., Mi, J., Dally, B. B., Craig, R. A., \& Wang, P. F. (2011). Premixed moderate or intense low-oxygen dilution (mild) combustion from a single jet burner in a labscale furnace. Energy Fuels, 25, 2782-2793.

Liu, F., Becker, H. A., \& Bindar, Y. (1998). A comprehensive study of radiative heat transfer modelling in gas fire furnace using the simple gray gas and the weight sum of gray gas models. International Journal of Heat and Mass Transfer, 41, $3357-3371$.

Maczulak, A. (2010). Renewable energy, sources and methods Facts on File. New York.

Mancini, M., Schwoppe, P., Weber, R., \& Orsino, S. (2007). On mathematical modelling of flameless combustion. Combustion and Flame, 150(1-2), 54-59.

Mastorakos, E. (2009). Ignition of turbulent non-premixed flames. Progress in Energy and Combustion Science, 35, 57-97.

Merci, B., Naud, B., \& Roekaerts, D. (2007). Impact of turbulent flow and mean mixture fraction results on mixing model behaviour in transported scalar pdf simulations of turbulent non-premixed bluff body flames flow. Turbulence and Combustion, 79, 41-53.

Nakamura, T., Smart, J. P., \& Van de Kamp, W. L. (1993). Combustion and emissions control. Cardiff, UK: Institute of Energy.

Neophytou, A., Richardson, E. S., \& Mastorakos, E. (2012). Spark ignition of turbulent recirculating non-premixed gas and spray flames: A model for predicting ignition probability. Combustion and Flame, 159, 1503-1522.

Noor, M. M., Wandel, A. P., \& Yusaf, T. (2012a). A review of mild combustion and open furnace design consideration. International Journal of Automotive and Mechanical Engineering, 6, 730-754.

Noor, M. M., Wandel, A. P., \& Yusaf, T. (2012b). The modelling of the effect of air fuel ratio on unburned hydrocarbons for mild combustion. Paper presented at the 2nd Malaysian Postgraduate Conference, Bond University, Gold Coast, Australia.

Noor, M. M., Wandel, A. P., \& Yusaf, T. (2012c). A preliminary study of control parameters for open furnace mild combustion using $c f d$. Paper presented at the 2nd Malaysian Postgraduate Conference, Bond University, Australia.

Noor, M. M., Wandel, A. P., \& Yusaf, T. (2013a). The analysis of recirculation zone and ignition position of non-premixed bluff-body for biogas mild combustion. Paper presented at the 2nd International Conference of Mechanical Engineering Research, Gambang, Malaysia.

Noor, M. M., Wandel, A. P., \& Yusaf, T. (2013b). Detail guide for cfd on the simulation of biogas combustion in bluff-body mild burner. Paper presented at the 2nd International Conference of Mechanical Engineering Research, Gambang, Malaysia.

Orsino, S., Weber, R., \& Bollettini, U. (2001). Numerical simulation of combustion of natural gas with high temperature air. Combustion Science \& Technology, 170(1), 1-34.

Parente, A., Galletti, C., \& Tognotti, L. (2011). A simplified approach for predicting no formation in mild combustion of ch4/h2 mixtures. Paper presented at the Proceedings of the Combustion Institute.

Peters, N. (2000). Turbulent combustion: Cambridge University Press.

Pope, S. B. (2000). Turbulent flows: Cambridge University Press.

Rafidi, N., \& Blasiak, W. (2006). Heat transfer characteristics of hitac heating furnace using regenerative burners. Applied Thermal Engineering, 26, 2027-2034. 
Riahi, Z., Mergheni, M. A., Sautet, J. C., \& Nasrallah, S. B. (2012). Numerical study of turbulent normal diffusion flame ch4-air stabilized by coaxial burner. Thermal Science, 1, 1-20.

Scharler, R., \& Obernberger, I. (2000). Numerical modelling of biomass grate furnace. Paper presented at the European Conference on Industrial Furnaces and Boilers (INFUB), Porto, Portugal.

Shih, T. H., Liou, W. W., Shabbir, A., Yang, Z., \& Zhu, J. (1995). A new k-e eddyviscosity model for high reynolds number turbulent flows-model development and validation. Computers and Fluids, 24(3), 227-238.

Smith, S. T., \& Fox, R. O. (2007). A term-by-term direct numerical simulation validation study of the multi environment conditional pdf model for turbulent reacting flows. Physics of Fluids, 19, 85-102.

Szegö, G. G., Dally, B. B., \& Christo, F. C. (2011). Investigation of the mixing patterns inside a mild combustion furnace based on cfd modelling. Paper presented at the Proceedings of the Australian Combustion Symposium, University of Newcastle, Australia.

Triantafyllidis, A., Mastorakos, E., \& Eggels, R. L. G. M. (2009). Large eddy simulations of forced ignition of a non-premixed bluff-body methane flame with conditional moment closure. Combustion \& Flame, 156, 2328-2345.

Tsuji, H., Gupta, A. K., \& Hasegawa, T. (2003). High temperature air combustion. Boca Raton, Florida: CRC Press.

Weber, R., Orsino, S., Lallemant, N., \& Verlann, A. (2000). Combustion of natural gas with high-temperature air and large quantities of flue gas. Paper presented at the Proceedings of the Combustion Institute.

Weber, R., Smart, J. P., \& Kamp, W. V. D. (2005). On the mild combustion of gaseous, liquid, and solid fuels in high temperature preheated air. Paper presented at the Proceedings of the Combustion Institute.

Wünning, J. (1991). Flammenlose oxidation von brennstoff mit hochvorgewärmter luft. Chem.-Ing.-Tech, 63(12), 1243-1245.

Yusaf, T., Noor, M. M., \& Wandel, A. P. (2013). Mild combustion: The future for lean and clean combustion. Paper presented at the 2nd International Conference of Mechanical Engineering Research, Gambang, Malaysia.

\section{NOMENCLATURES}

CFD Computational fluid dynamics

$\mathrm{CO}_{2}$ Carbon dioxide

EGR Exhaust gas recirculation

GHG Greenhouse gas
IEA International Energy Agency

LCV Low calorific value

$\mathrm{NO}_{\mathrm{x}}$ Nitrogen oxides

UHC Unburned hydrocarbons 